\title{
Composition-dependent variation of magnetic properties and interstitial ordering in homogeneous expanded austenite
}

Brink, Bastian K.; Ståhl, Kenny; Christiansen, Thomas Lundin; Frandsen, Cathrine; Hansen, Mikkel Fougt; Somers, Marcel A. J.

\section{Published in:}

Acta Materialia

Link to article, DOI:

10.1016/j.actamat.2015.12.043

Publication date:

2016

Document Version

Peer reviewed version

Link back to DTU Orbit

Citation (APA):

Brink, B. K., Ståhl, K., Christiansen, T. L., Frandsen, C., Hansen, M. F., \& Somers, M. A. J. (2016). Compositiondependent variation of magnetic properties and interstitial ordering in homogeneous expanded austenite. Acta Materialia, 106, 32-39. https://doi.org/10.1016/j.actamat.2015.12.043

\section{General rights}

Copyright and moral rights for the publications made accessible in the public portal are retained by the authors and/or other copyright owners and it is a condition of accessing publications that users recognise and abide by the legal requirements associated with these rights.

- Users may download and print one copy of any publication from the public portal for the purpose of private study or research.

- You may not further distribute the material or use it for any profit-making activity or commercial gain

- You may freely distribute the URL identifying the publication in the public portal 


\title{
Composition-dependent variation of magnetic properties and
}

\section{interstitial ordering in homogeneous expanded austenite}

Bastian K. Brink ${ }^{\mathrm{a}}$, Kenny Ståhl ${ }^{\mathrm{b}}$, Thomas L. Christiansen ${ }^{\mathrm{a}}$, Cathrine Frandsen ${ }^{\mathrm{c}}$, Mikkel Fougt Hansen $^{\mathrm{d}}$, Marcel A. J. Somers ${ }^{\mathrm{a}, *}$

${ }^{\text {a }}$ Department of Mechanical Engineering, Technical University of Denmark, Produktionstorvet B425, DK-2800 Kgs. Lyngby, Denmark

${ }^{\mathrm{b}}$ Department of Chemistry, Technical University of Denmark, Kemitorvet B206, DK-2800 Kgs. Lyngby, Denmark

${ }^{\text {c } D e p a r t m e n t ~ o f ~ P h y s i c s, ~ T e c h n i c a l ~ U n i v e r s i t y ~ o f ~ D e n m a r k, ~ F y s i k v e j ~ B 307, ~ D K-2800 ~ K g s . ~}$ Lyngby, Denmark

${ }^{\mathrm{d}}$ Department of Micro- and Nanotechnology, Technical University of Denmark, Ørsteds Plads B344, DK-2800 Kgs. Lyngby, Denmark

*somers@mek.dtu.dk

\begin{abstract}
The crystal structure and magnetic properties of austenitic stainless steel with a colossal interstitial content, so-called expanded austenite, are currently not completely understood. In the present work, the magnetic properties of homogeneous samples of expanded austenite, as prepared by low-temperature nitriding of thin foils, were investigated with magnetometry and Mössbauer spectroscopy. At room temperature, expanded austenite is paramagnetic for relatively low and for relatively high nitrogen contents $\left(y_{N}=0.13\right.$ and 0.55 , respectively, where $y_{N}$ is the interstitial nitrogen occupancy), while ferromagnetism is observed for intermediate nitrogen loads. Spontaneous volume magnetostriction was observed in the ferromagnetic state and the Curie temperature was found to depend strongly on the nitrogen content. For the first time, X-ray diffraction evidence for the occurrence of long-range
\end{abstract}


interstitial order of nitrogen atoms in expanded austenite was observed for high nitrogen contents.

Keywords: Low temperature surface hardening, Gas nitriding, Expanded austenite, Magnetostriction, Mössbauer spectroscopy

\section{Introduction}

Expanded austenite, also commonly referred to as S-phase, is a solid solution of a large (colossal) quantity of nitrogen (and/or carbon) in an f.c.c. Fe-based lattice with substitutional elements with a higher affinity for interstitials than iron. Such a solution is formed by the dissolution of nitrogen (and/or carbon) into austenitic stainless steel, while preventing the formation of nitrides (and/or carbides) by choosing a treatment temperature where the substitutionally dissolved atoms can be effectively considered immobile as compared to interstitially dissolved atoms. On dissolving nitrogen into austenitic stainless steel by nitriding below approximately $720 \mathrm{~K}$, a solid solution is obtained with up to 38 at.\% N, corresponding to an occupancy of the f.c.c. sublattice of octahedral interstices of $y_{\mathrm{N}}=0.61$ [1]. Obviously, the dissolution of interstitials at relatively low temperatures is limited to case depths of several tens of microns as a consequence of the competition between interstitial diffusion and the formation of nitrides or carbides. Treated austenitic stainless steels exhibit enhanced surface hardness of up to 1.4 GPa leading to improved wear resistance [2,3], while the corrosion performance is retained or even improved, in particular concerning localized corrosion $[4,5]$.

A complete description of the crystal structure of expanded austenite is currently not available. Ten possible candidate structures were recently evaluated but all failed in correctly describing the experimental observations from X-ray diffraction (XRD) investigations [6]. Generally, inhomogeneous samples consisting of an expanded austenite surface zone on bulk 
stainless steel were used for crystal structure determination, implying that a functionally graded material with steep composition and (substantial) residual stress gradients were attempted to be reconciled with a crystal structure. The resulting depth variation in composition causes asymmetric broadening of diffraction peaks, and the induced macro-stress gradient over the expanded austenite zone causes $h k l$-dependent shifts of peak positions as a consequence of nitrogen-concentration dependent elastic anisotropy [7-11]. Furthermore, as a consequence of lattice rotations induced by plastic accommodation of the lattice expansion, texture and micro-strain gradients occur over the expanded austenite case $[12,13]$. Currently, the best structural description for homogeneous samples [14] is an f.c.c. lattice with stacking faults contributing to systematic deviations of XRD peaks as described in Ref. [15].

The f.c.c. structure of iron (austenite, $\gamma$-Fe) has been predicted to exhibit either nonmagnetic (paramagnetic), antiferromagnetic or ferromagnetic behavior, depending on the separation of the iron atoms $[16,17]$. The ferromagnetic state is stabilized by larger interatomic distances and has been observed experimentally for epitaxial $\gamma$-Fe films grown on $\mathrm{Cu}$ and $\mathrm{Cu}_{3} \mathrm{Au}[18,19]$. Room temperature ferromagnetism has been reported for nitrogen expanded austenite $\left(\gamma_{N}\right)[7,20,21]$ and is mainly attributed to the lattice expansion caused by incorporation of large amounts of nitrogen atoms, possible areas enriched in Fe and $\mathrm{Ni}$ and the similarity to the structure of $\gamma^{\prime}-\mathrm{Fe}_{4} \mathrm{~N}$, which is ferromagnetic at room temperature [22]. Ferromagnetic carbon expanded austenite $\left(\gamma_{C}\right)$ has so far not been observed, which is in agreement with a limited carbon solubility and associated modest lattice expansion compared to nitrogen expanded austenite [23].

Similarly for published results on the crystal structure, available literature on Mössbauer studies and magnetic properties of expanded austenite is focused on specimens with gradients in composition and residual stresses [7,20,21,24-27], which is likely to influence the obtained results. In the current investigation the relation between interstitial content and magnetic 
properties is, for the first time, explored for homogeneous samples of nitrogen expanded austenite.

\section{Experimental}

\subsection{Sample preparation}

Thin foils of AISI 316 stainless steel of nominal composition (by mass) 18\% Cr, 10\% Ni and 3\% Mo (Goodfellow Cambridge Ltd.) with thickness $12.5 \mu \mathrm{m}$ were used for nitriding. Prior to nitriding, recrystallization and austenitization was achieved by heating to $1323 \mathrm{~K}$ in pure $\mathrm{H}_{2}$ followed by immediate cooling to room temperature. A pretreatment was applied, which involves chemical stripping of the passive oxide film, followed by electrochemical deposition of $\mathrm{Ni}$ in a Wood's nickel bath, containing $\mathrm{NiCl}_{2}, \mathrm{NiSO}_{4}$ and $\mathrm{H}_{2} \mathrm{SO}_{4}$. The deposited nickel contributes to less than 0.5 percent of the total mass of the foils, cf. Ref. [1]. The thin electrodeposited nickel layer prevents repassivation of the stainless steel and catalyzes the dissociation of ammonia at the surface. Gaseous nitriding of the foil pieces was performed in a Netzsch STA 449 F3 Jupiter thermal analyzer with samples in ceramic crucibles using ammonia, hydrogen and nitrogen gasses of 99.999\% purity. Total flow rates of $155-255 \mathrm{~mL} / \mathrm{min}$ were used with a constant $\mathrm{N}_{2}$ flow of $5 \mathrm{~mL} / \mathrm{min}$ for protection of electronics in the measurement compartment.

A fully nitrided sample was synthesized in an atmosphere of $97 \mathrm{vol} . \% \mathrm{NH}_{3}$ and 3 vol.\% $\mathrm{N}_{2}$ (infinite nitriding potential, $K_{\mathrm{N}}=p\left(\mathrm{NH}_{3}\right) / p\left(\mathrm{H}_{2}\right)^{3 / 2}$, where $p$ is the partial pressure) at 693 K for 13 hours. Three additional samples were synthesized by lowering the nitriding potentials to 2.40, 0.07 and $0\left(\mathrm{~atm}^{-1 / 2}\right)$ after full saturation was achieved. Lowering the nitriding potential after saturation leads to denitriding of the foils until equilibrium (or a stationary state) is achieved between the nitrogen content in the foil and the adjusted nitriding potential in the gas phase. The thus nitrided foils were powdered with ultra-sound while 
submerged in ethanol and, subsequently, dried in air. As reference, a sample of $\gamma^{\prime}-\mathrm{Fe}_{4} \mathrm{~N}$ was prepared by nitriding iron powder with a mean particle size of $6-8 \mu \mathrm{m}(99.0+\%$ purity, Goodfellow Cambridge Ltd.) at $718 \mathrm{~K}$ in a gas mixture with a nitriding potential of $K_{\mathrm{N}}=1.45$ $\mathrm{atm}^{-1 / 2}$, conforming to an equilibrium nitrogen content of $y_{\mathrm{N}}=0.249$ [28]. For determination of the lattice parameter, X-ray diffraction patterns were recorded with an Agilent SuperNova diffractometer with an Atlas S2 CCD detector using Mo $K_{\alpha}$ radiation and calibrated with a $\mathrm{LaB}_{6}$ standard, with samples mounted on adhesive tape.

\subsection{Magnetometry and Mössbauer spectroscopy:}

Characterization of the magnetic properties was performed with a Lake Shore Cryotronics 7400 Series Vibrating Sample Magnetometer (VSM) equipped with either a single-stage variable temperature option (model 74035) or a low-temperature variable temperature cryostat

(model 74018). The ${ }^{57}$ Fe Mössbauer spectra were recorded using conventional constant acceleration spectrometers with sources of ${ }^{57} \mathrm{Co}$ in $\mathrm{Rh}$ on samples mixed with boron nitride powder. Spectra obtained at low temperatures were recorded in a closed cycle helium refrigerator (APD Cryogenics) and isomer shifts are given with respect to that of $\alpha$-Fe at room temperature. Mössbauer spectra were fitted with Lorentzian doublets constrained to equal width and intensity of the two lines and sextets were fitted with Voigt line profiles constrained to an intensity ratio of 3:2:1:1:2:3, with the Gaussian component describing a distribution in hyperfine fields. Isomer shifts were fitted separately for each component and quadrupole shifts were fixed to zero.

\subsection{In situ $X$-ray diffraction}

For investigation of possible magneto volume effects on the thermal expansion of expanded austenite, an additional sample with a composition in-between those of the 
ferromagnetic samples (see below) was prepared similarly to the description in Section 2.1 using a gas mixture corresponding to a nitriding potential of $K_{\mathrm{N}}=0.28 \mathrm{~atm}^{-1 / 2}$. Synchrotron $\mathrm{X}$-ray diffractograms were collected up to a temperature of $890 \mathrm{~K}$ at a wavelength, $\lambda=$ 0.99471(2) Å from samples in sealed quartz capillaries with a Huber G670 Guinier camera at MAX-lab beamline I711 [29]. W powder (99.95\% purity, Goodfellow Cambridge Ltd.) was used as internal standard for temperature calibration. For all Rietveld refinements, residual values of $R_{\mathrm{p}} \leq 1.11 \%$ and goodness-of-fit values $\chi^{2} \leq 2.37$ were obtained. Additional details for in situ synchrotron X-ray diffraction and Rietveld refinements are provided elsewhere $[30,31]$.

\section{Results and interpretation}

\subsection{X-ray diffraction}

X-ray diffractograms used for determination of lattice parameters and stacking fault probabilities are shown in Fig. 1. The interstitial nitrogen content can be estimated from the lattice parameter, $a$, using the reported relation between $a$ and the interstitial nitrogen occupancy, $y_{\mathrm{N}}[1]$. The obtained lattice parameter for denitriding at zero nitrogen potential is larger than for the untreated austenitic stainless steel, but below the minimum value in the reported relation. Consequently, the relation applying for low interstitial contents, as reported for carbon-expanded austenite [23], was used for this sample, improving the agreement with thermogravimetric results. The nitrogen occupancies thus determined from the lattice parameter as well as the obtained stacking fault probabilities are given in Table 1.

\subsection{Magnetometry}

Magnetic hysteresis curves measured at room temperature are presented in Fig. 2(a). Analogous to $\gamma^{\prime}-\mathrm{Fe}_{4} \mathrm{~N}$, expanded austenite with an intermediate nitrogen content $\left(y_{\mathrm{N}}=0.29\right.$ 
and 0.38) displays only limited hysteresis and can thus be classified as a soft ferromagnet. The specific saturation magnetizations for the two compositions are identical within experimental accuracy and significantly lower than for $\gamma^{\prime}-\mathrm{Fe}_{4} \mathrm{~N}$ (Table 2). Note that the situation is reversed at low external fields, with expanded austenite exhibiting the highest magnetization.

For both low and high nitrogen contents $\left(y_{\mathrm{N}}=0.13\right.$ and 0.55$)$, only a small ferromagnetic contribution is apparent from the hysteresis curves. This is attributed to the presence of ferrite impurities, and was verified by $X$-ray diffraction for $y_{N}=0.13$ (not shown). Ferrite impurities are likely present in all samples, but for higher nitrogen contents the ferrite Bragg reflections overlap with the broadened and shifted reflections from expanded austenite. For low and high nitrogen contents, expanded austenite is thus paramagnetic at room temperature. In the temperature range down to $80 \mathrm{~K}$ no distinct magnetic transition was observed in the magnetization curves for these samples (Fig. 2b).

The Curie temperature, $T_{\mathrm{C}}$, was taken as the zero-point of the second derivative of magnetization vs. temperature curves [32]. For $\gamma^{\prime}-\mathrm{Fe}_{4} \mathrm{~N}$, the obtained $T_{\mathrm{C}}$ is in agreement with the literature value of $767 \pm 10 \mathrm{~K}$ [22]. Analogous to the saturation magnetization, Curie temperatures for the ferromagnetic compositions of expanded austenite are lower than for $\gamma^{\prime}-$ $\mathrm{Fe}_{4} \mathrm{~N}$ (Table 2).

\subsection{Mössbauer spectroscopy}

The absence of magnetically split components in Mössbauer spectra for $y_{N}=0.13$ and 0.55 (Fig. 3) supports the results from the magnetometry investigations, that expanded austenite is paramagnetic at room temperature for low and high nitrogen contents, as is also 
the case for the untreated austenitic stainless steel. The volume fraction of the ferrite impurity is so low that it is indistinguishable from the background.

In Mössbauer spectra of unalloyed $\gamma$-Fe, the only observed component should be a singlet. The addition of alloying elements results in quadrupole split doublets as a consequence of local variations in symmetry caused by nearest and second-nearest neighbor configurations of both substitutional and interstitial elements [33]. The Mössbauer spectrum of the untreated steel can be reasonably described by a single doublet $\left(\gamma^{0}\right)$ implying that an effective average of these effects is taken (Fig. 3d).

Fitting the Mössbauer spectrum for expanded austenite with $y_{\mathrm{N}}=0.13$ requires (at least) one additional component (Fig. 3e). This doublet $\left(\gamma^{\mathrm{I}}\right)$ can be attributed to iron atoms with one nitrogen nearest neighbor [34]. The average coordination number of Fe, $c_{\mathrm{N}}$, can be calculated as the sum of the relative contributions of the doublet components multiplied by the corresponding number of nitrogen neighbors. For the two doublet components corresponding to zero and one $\mathrm{N}$ neighbor, this yields a value of $c_{\mathrm{N}}=0.53$. As the coordination number for a random distribution of nitrogen over all available octahedral sites would correspond to $c_{\mathrm{N}}=$ 0.78 for a total interstitial content $y_{\mathrm{N}}=0.13$, it is concluded that Fe atoms are less likely coordinated by nitrogen atoms than other substitutional elements. This agrees favorably with previous EXAFS results, which showed that short-range ordering (SRO) between $\mathrm{N}$ and $\mathrm{Cr}$ effectively reduces the coordination number of Fe; here it was found that for denitrided expanded austenite the coordination number of Fe was $c_{\mathrm{N}}<0.55$ [35].

For the sample with the highest nitrogen content, the Mössbauer spectrum is fitted with three doublets (Fig. 3f). The corresponding Fe environments can be interpreted in terms of a point-charge approximation [34]: The first component $\left(\gamma^{\mathrm{II}}\right)$ corresponds to Fe with two $\mathrm{N}$ neighbors at opposite octahedral sites, i.e. separated by $180^{\circ}$. The two additional doublets have quadrupole splittings in a 2:1 ratio and similar isomer shifts, which are larger than for 
any of the previous doublets (Table 3). These observations are consistent with Fe having four nitrogen atoms as nearest neighbors. The nitrogen atoms may either be arranged in a planar configuration where the two remaining empty sites are separated by $180^{\circ}$, on opposite sides of $\mathrm{Fe}\left(\gamma^{\mathrm{IV} \alpha}\right)$, or with two adjacent empty sites, separated by $90^{\circ}\left(\gamma^{\mathrm{IV} \beta}\right)$. The coordination number calculated from the relative contributions of the doublet components is $c_{\mathrm{N}}=3.3$, which is the expected value for a total nitrogen content $y_{\mathrm{N}}=0.55$. This suggests that the coordination of iron atoms by nitrogen is not affected by SRO between $\mathrm{Cr}$ and $\mathrm{N}$, and could imply that SRO is not dominant for high nitrogen contents.

For the samples of intermediate nitrogen content $\left(y_{N}=0.29\right.$ and 38) the magnetically split spectra could not be fitted with a reasonable number of individual sextets corresponding to specific coordination of nitrogen atoms. Therefore, approximate fits were obtained by using two components, each with a Gaussian distribution of hyperfine fields, as shown in Fig. $3(b+c)$. The two components do not have a specific physical meaning but were necessary in order to allow the fits to represent the measured spectra. The average isomer shifts are between those of expanded austenite with low and high nitrogen contents. The average hyperfine fields (Table 4) are somewhat lower than typically found for Fe with two N nearest neighbors in $\gamma^{\prime}-\mathrm{Fe}_{4} \mathrm{~N}$, which is between 21.4 and $22.0 \mathrm{~T}$ [36]. Compared to the (strictly ${ }^{1}$ ) long-range ordered iron nitride, the lack of well-defined sextets for expanded austenite indicates a less ordered structure.

The Mössbauer spectrum of the untreated steel at $15 \mathrm{~K}$ (Fig. 4a) is broader than at room temperature (Fig. 3d). This broadening is due to a transition from a paramagnetic to an antiferromagnetic state below about $23 \mathrm{~K}$ [37]. Similar broadening is observed for expanded austenite with $y_{\mathrm{N}}=0.13$, presumably caused by an analogous paramagnetic-toantiferromagnetic transition. Both Mössbauer spectra are fitted with one sextet; a larger

\footnotetext{
${ }^{1}$ The long-range order parameter of $\gamma^{\prime}-\mathrm{Fe}_{4} \mathrm{~N}$ is close to 1.
} 
hyperfine field is observed for expanded austenite than for untreated austenite. The only evident change for intermediate nitrogen contents is an increase of the average isomer shifts and hyperfine fields compared to room temperature values. Unlike expanded austenite with a low nitrogen content, the sample with $y_{\mathrm{N}}=0.55$ displays distinct magnetic splitting at $15 \mathrm{~K}$. The resemblance of the spectrum to those of $y_{\mathrm{N}}=0.29$ and 0.38 indicates ferromagnetic ordering, albeit with a lower average hyperfine field. Since no distinct transition was observed in magnetization measurements, the Curie temperature for $y_{\mathrm{N}}=0.55$ must be in the range 15 to $80 \mathrm{~K}$.

\subsection{Thermal expansion}

The magneto volume effects on the thermal expansion of expanded austenite was studied for an additional sample with a nitrogen content corresponding to occupation of one third of the octahedral interstitial positions $\left(y_{N}=0.33\right)$. This nitrogen content is within the ferromagnetic compositional range since it is in-between that of the two compositions determined to be ferromagnetic at room temperature $\left(y_{\mathrm{N}}=0.29\right.$ and 0.38$)$.

The variation in lattice parameter for expanded austenite with increasing temperature, obtained with in situ synchrotron X-ray diffraction, is shown in Fig. 5. In contrast to previous findings for both high and low nitrogen contents [30], the thermal expansion of the lattice for the current sample $\left(y_{N}=0.33\right)$ cannot be described by a single linear relation for the entire investigated temperature range. Instead, two distinct linear regions are identified, described by $a(T)=a_{T r}\left[1+\alpha\left(T-T_{r}\right)\right]$, where $a$ is the lattice parameter of the unit cell and $a_{T r}$ is the lattice parameter at a chosen reference temperature, $T_{r}$. In the low-temperature range, $341-549 \mathrm{~K}$, the expansion coefficient is $9.66(4) \times 10^{-6} \mathrm{~K}^{-1}$, which is considerably lower than for other nitrogen contents [30] and closer to that of $\gamma^{\prime}-\mathrm{Fe}_{4} \mathrm{~N}$ [38]. In the high temperature range, $572-$ $808 \mathrm{~K}$, the expansion coefficient is $15.3(1) \times 10^{-6} \mathrm{~K}^{-1}$. This value is similar to, but slightly 
higher than that observed for high nitrogen contents and lower than that observed for austenite with a low or zero interstitial content [30].

\section{Discussion}

\subsection{Interstitial ordering}

Since Mössbauer spectra for paramagnetic expanded austenite are not well-resolved, other interpretations involving additional components than the currently applied doublets are possible. Alternative, but rejected, fits could be interpreted in terms of components corresponding to iron atoms surrounded by five nitrogen atoms or with nitrogen atoms in tetrahedral positions, which are deemed to be less likely than the presented interpretation. Exact interpretations are complicated by the fact that the quadrupole splitting is not only affected by the number and configuration of neighboring nitrogen atoms [34], but also interstitial second nearest neighbors [39] and surrounding substitutional elements [33]. Overall changes in symmetry of the octahedral coordination environment should also be taken into account, since an apparent deviation from cubic symmetry, as evidenced by X-ray diffraction, is one of the primary features of expanded austenite. These effects could explain why the quadrupole splittings of components $\gamma^{\mathrm{II}}$ and $\gamma^{\mathrm{IV} \alpha}$ are not equal as expected from a point-charge approximation. It should, however, be noted that the validity of this approximation is limited, even in the absence of substitutional elements [34].

The lack of a component attributed to iron surrounded by three nitrogen atoms for $y_{N}=$ 0.55 signifies a clear deviation from a random distribution of nitrogen. Interstitial ordering is expected to cause additional reflections (systematically extinct for f.c.c. structures) in diffraction patterns, as is the case for the primitive cubic structure of $\gamma^{\prime}-\mathrm{Fe}_{4} \mathrm{~N}$. For expanded austenite these reflections have consistently not been observed with X-ray diffraction but have been observed using selected-area electron diffraction [40], suggesting that small ordered 
domains do exist. A close inspection of the X-ray diffractogram for $y_{N}=0.55$ does reveal the presence of 110 and 112 reflections (Fig. 6). The slight discrepancy between ideal and observed peak positions is a common feature for expanded austenite.

The structure of $\gamma^{\prime}-\mathrm{Fe}_{4} \mathrm{~N}$, in which Fe has either no or two $\mathrm{N}$ neighbors, can be considered as an f.c.c. arrangement of Fe with $\mathrm{N}$ located at the body-centered octahedral site. A structure composed of metal atoms with only two or four nitrogen neighbors (components $\gamma^{\mathrm{II}}$ and $\gamma^{\mathrm{IV} \alpha}$ ) can be realized with additional $\mathrm{N}$ in octahedral sites on one set of parallel cube edges. Additional reflections indicating a larger unit cell, which would be required for an ordered structure incorporating also component $\gamma^{\mathrm{IV} \beta}$, were not observed. This arrangement must therefore be realized by short-range ordering.

Isomer shifts of the fitted components increase both as a result of lattice expansion, which reduces the s-electron density at the iron nuclei, and with increased number of nitrogen neighbors. The increase caused by nitrogen nearest neighbors may be explained from an increased screening effect from $d$-electrons due to hybridization of nitrogen $2 p$ states with the iron $3 d$ band as in $\gamma^{\prime}-\mathrm{Fe}_{4} \mathrm{~N}[41]$.

\subsection{Spontaneous volume magnetostriction}

The Curie temperatures determined for $y_{\mathrm{N}}=0.29$ and 0.38 (501 and $520 \mathrm{~K}$, respectively) are lower than the temperature around $560 \mathrm{~K}$, at which a change in thermal expansion coefficients is observed for $y_{\mathrm{N}}=0.33$. As seen from Fig. 2(b), the magnetic transition is not sharply defined and an entirely paramagnetic state is first achieved above $550 \mathrm{~K}$. This strongly indicates that the change in expansion coefficient is associated with variations in magnetic properties. The relatively low expansion coefficient for ferromagnetic expanded austenite with intermediate nitrogen content is thus likely the result of spontaneous volume magnetostriction in the ferromagnetic state. This is similar to the effect responsible for the 
low (virtually zero) coefficient of thermal expansion for Invar alloys [42], albeit not as pronounced for the present case. This magnetic effect on lattice parameters may also explain why the reported relation between lattice parameter and interstitial content for nitrogen expanded austenite [1] appears to be shifted to higher values relative to this relation for carbon expanded austenite [21], and does not include the value for the untreated steel at $y_{\mathrm{N}}=$ 0, as shown on Fig. 7. No ferromagnetic transition has been reported for carbon expanded austenite, which is consistent with a lower solubility of carbon as compared to nitrogen, yielding a lattice expansion limited to about 3\% [23], i.e. insufficient to induce the transition to ferromagnetic austenite.

Assuming that the incompatible relations between lattice parameter and interstitial content for nitrogen and carbon expanded austenite are caused by spontaneous volume magnetostriction, the following is obtained: The difference in lattice parameter for (ferromagnetic) nitrogen and (paramagnetic) carbon expanded austenite for an interstitial occupancy of $y_{\mathrm{N} / \mathrm{C}}=0.17$ is $1.1 \%$. This corresponds to a spontaneous volume magnetostriction of 3.5\% at room temperature, which is higher than for traditional Fe-Ni Invar alloys [43]. Another estimate for the spontaneous volume magnetostriction can be obtained from extrapolating the difference in thermal expansion coefficient between paramagnetic and ferromagnetic expanded austenite with $y_{N}=0.33$ to room temperature. This yields a value for the spontaneous volume magnetostriction of $1.5 \%$, which is consistent with a decreasing magnetic contribution with increasing nitrogen content as shown in Fig. 7.

According to Fig. 7, the discrepancy between nitrogen and carbon expanded austenite occurs at $y_{\mathrm{N} / \mathrm{C}}=0.17$, which suggests that ferromagnetism occurs for an expansion of the lattice parameter of about $4.2 \%$ as compared to interstitial free austenite. This is in excellent agreement with magnetic force microscopy and Auger electron microscopy investigations on 
(functionally graded and strained) expanded austenite layers, where a 5\% expansion was estimated for the transition from paramagnetic to ferromagnetic austenite [11].

The connection between a ferromagnetic transition and the discontinuity in the compositionally induced lattice expansion for expanded austenite has previously been noted [44]. The reported difference in lattice parameter in Ref. [44] does, however, correspond to a spontaneous volume magnetostriction of about $14 \%$, which seems unreasonably high. This result is likely due to the applied correction for "Poisson expansion” due to compressive residual stress in the expanded austenite zone, using the elastic constants for austenitic stainless steel. For expanded austenite, the elastic constants change with interstitial content and the elastic anisotropy is reversed $[10,45]$. This change in elastic anisotropy is likely to be related to the paramagnetic-to-ferromagnetic transition.

\subsection{Implications for surface engineering of stainless steels by nitriding}

Concentration-dependent magnetic properties and associated Curie temperatures and spontaneous volume magnetostriction have implications for the practical application of expanded austenite zones on nitrided stainless steels. In industrial practice, expanded austenite is present as a functionally-graded surface zone, a so-called case, where the concentration of interstitials changes from a high concentration at the surface to a concentration representing the bulk concentration prior to surface treatment. The present investigations show that expanded austenite developing at the usual processing temperature, which is typically above $673 \mathrm{~K}$, is paramagnetic and that a transition from paramagnetism to ferromagnetism occurs during cooling. Along with this magnetic transformation, the thermal expansion coefficient changes as a consequence of spontaneous volume magnetostriction. The Curie temperature and the thermal expansion coefficients depend on the nitrogen content while carbon expanded austenite has so far not shown a magnetic transition. Then, in addition to the composition-induced strains in the expanded austenite zone, as present at the treatment 
temperature, thermal strains are superimposed during cooling because of composition dependent thermal expansion coefficients and a composition-dependent temperature where spontaneous volume magnetostriction is introduced. Whether these strains are manifested as residual stresses depends on whether the strains are accommodated elastically or plastically.

For industrial applications where ferromagnetic expanded austenite is undesired, it is of utmost importance to control the interstitial content to below, say $y_{\mathrm{N} / \mathrm{C}}=0.17$, irrespective of whether nitrogen or carbon is interstitially dissolved.

\section{Conclusions}

For low $\left(y_{\mathrm{N}}=0.13\right)$ and high nitrogen contents $\left(y_{\mathrm{N}}=0.55\right)$, expanded austenite is paramagnetic at room temperature, while it is ferromagnetic at intermediate nitrogen contents $\left(y_{\mathrm{N}}=0.29\right.$ and 0.38$)$. Spontaneous volume magnetostriction in the ferromagnetic state explains why the linear relation reported between lattice parameter and interstitial content for nitrogen expanded austenite does not include the value of the untreated steel for $y_{\mathrm{N}}=0$. In addition, magnetostriction affects the coefficients of thermal expansion.

For the first time, X-ray diffraction evidence was obtained for the occurrence of longrange ordering of interstitially dissolved nitrogen in expanded austenite. Long-range ordering was only observed for the highest nitrogen content investigated, $y_{\mathrm{N}}=0.55$.

\section{Acknowledgements}

The authors are grateful to Danscatt for financing the measurement time at MAX-lab and to Jeppe Fock for assistance with fitting of Mössbauer spectra. The Danish Council for Independent Research (DFF) is gratefully acknowledged for financial support under Grant 11106293. 


\section{References}

[1] T. Christiansen, M.A.J. Somers, Controlled Dissolution of Colossal Quantities of Nitrogen in Stainless Steel, Metall. Mater. Trans. A. 37 (2006) 675-682.

[2] Y. Sun, T. Bell, Sliding wear characteristics of low temperature plasma nitrided 316 austenitic stainless steel, Wear. 218 (1998) 34-42.

[3] T. Christiansen, M.A.J. Somers, Low temperature gaseous nitriding and carburising of stainless steel, Surf. Eng. 21 (2005) 445-455.

[4] A. Fossati, F. Borgioli, E. Galvanetto, T. Bacci, Corrosion resistance properties of glow-discharge nitrided AISI 316L austenitic stainless steel in $\mathrm{NaCl}$ solutions, Corros. Sci. 48 (2006) 1513-1527.

[5] C.X. Li, T. Bell, Corrosion properties of active screen plasma nitrided 316 austenitic stainless steel, Corros. Sci. 46 (2004) 1527-1547.

[6] M.P. Fewell, J.M. Priest, High-order diffractometry of expanded austenite using synchrotron radiation, Surf. Coatings Technol. 202 (2008) 1802-1815.

[7] O. Öztürk, D.L. Williamson, Phase and composition depth distribution analyses of low energy, high flux N implanted stainless steel, J. Appl. Phys. 77 (1995) 3839-3850.

[8] X. Xu, L. Wang, Z. Yu, J. Qiang, Z. Hei, Study of Microstructure of Low-Temperature Plasma-Nitrided AISI 304 Stainless Steel, Metall. Mater. Trans. A. 31 (2000) 11931199.

[9] T.L. Christiansen, T.S. Hummelshøj, M.A.J. Somers, Expanded austenite, crystallography and residual stress, Surf. Eng. 26 (2010) 242-247.

[10] F.A.P. Fernandes, T.L. Christiansen, G. Winther, M.A.J. Somers, On the determination of stress profiles in expanded austenite by grazing incidence X-ray diffraction and successive layer removal, Acta Mater. 94 (2015) 271-280.

[11] D. Wu, H. Kahn, G.M. Michal, F. Ernst, a. H. Heuer, Ferromagnetism in interstitially hardened austenitic stainless steel induced by low-temperature gas-phase nitriding, Scr. Mater. 65 (2011) 1089-1092.

[12] J.C. Stinville, P. Villechaise, C. Templier, J.P. Rivière, M. Drouet, Lattice rotation induced by plasma nitriding in a 316L polycrystalline stainless steel, Acta Mater. 58 
[13] J.C. Stinville, J. Cormier, C. Templier, P. Villechaise, Modeling of the lattice rotations induced by plasma nitriding of 316L polycrystalline stainless steel, Acta Mater. 83 (2015) 10-16.

[14] T. Christiansen, M.A.J. Somers, On the crystallographic structure of S-phase, Scr. Mater. 50 (2004) 35-37.

[15] B.E. Warren, X-Ray Diffr., Massachusetts: Addison-Wesley, 1969: pp. 275-298.

[16] V.L. Moruzzi, P.M. Marcus, K. Schwarz, P. Mohn, Ferromagnetic phases of bcc and fcc Fe, Co, and Ni, Phys. Rev. B. 34 (1986) 1784-1791.

[17] C.S. Wang, B.M. Klein, H. Krakauer, Theory of Magnetic and Structural Ordering in Iron, Phys. Rev. Lett. 54 (1985) 1852-1855.

[18] W. Keune, T. Ezawa, W.A.A. Macedo, U. Glos, K.P. Schletz, U. Kirschbaum, Magneto-volume effects in $\gamma$-Fe ultrathin films and small particles, Phys. B Condens. Matter. 161 (1989) 269-275.

[19] R.F. Willis, J.A.C. Bland, W. Schwarzacher, Ferromagnetism in ultrathin metastable films of fcc Fe, Co, and Ni (invited), J. Appl. Phys. 63 (1988) 4051-4056.

[20] E. Menéndez, C. Templier, P. Garcia-Ramirez, J. Santiso, A. Vantomme, K. Temst, et al., Magnetic properties of single crystalline expanded austenite obtained by plasma nitriding of austenitic stainless steel single crystals, ACS Appl. Mater. Interfaces. 5 (2013) 10118-10126.

[21] M.P. Fewell, D.R.G. Mitchell, J.M. Priest, K.T. Short, G.A. Collins, The nature of expanded austenite, Surf. Coatings Technol. 131 (2000) 300-306.

[22] G. Shirane, W.J. Takei, S.L. Ruby, Mössbauer Study of Hyperfine Fields and Isomer Shifts in Fe4N and (Fe,Ni)4N, Phys. Rev. 126 (1962) 49-52. http://scholar.google.com/scholar?hl=en\&btnG=Search\&q=intitle:No+Title\#0 (accessed January 13, 2015).

[23] T.S. Hummelshøj, T.L. Christiansen, M.A.J. Somers, Lattice expansion of carbonstabilized expanded austenite, Scr. Mater. 63 (2010) 761-763.

[24] Y. Jirásková, S. Oldřich, C. Blawert, Changes in austenitic steel surface induced by thermal and implantation treatments studied by Mössbauer spectroscopy, Surf. 
Interface Anal. 38 (2006) 348-351.

[25] Y. Jirásková, O. Schneeweiss, S. Havlíček, C. Blawert, H. Kalvelage, Surface modification of stainless steels by carbon/nitrogen implantation, Czechoslov. J. Phys. 51 (2001) 693-701. <Go to ISI >://000170360600006.

[26] O. Öztürk, M. Fidan, S. Mändl, MFM imaging of expanded austenite formed on 304 SS and CoCrMo alloys, Surf. Coatings Technol. 256 (2014) 15-22.

[27] H. Binczycka, M. Kahle, S. Cusenza, E. Carpene, P. Schaaf, Interstitial ordering of nitrogen and carbon in laser nitrided and laser carburized austenitic stainless steel, J. Phys. Condens. Matter. 18 (2006) 10561-10570.

[28] M.A.J. Somers, E.J. Mittemeijer, Layer-growth kinetics on gaseous nitriding of pure iron: Evaluation of diffusion coefficients for nitrogen in iron nitrides, Metall. Mater. Trans. A. 26 (1995) 57-74.

[29] Y. Cerenius, K. Ståhl, L.A. Svensson, T. Ursby, A. Oskarsson, J. Albertsson, et al., The crystallography beamline I711 at MAX II, J. Synchrotron Radiat. 7 (2000) 203-8.

[30] B. Brink, K. Ståhl, T.L. Christiansen, M.A.J. Somers, Thermal expansion and phase transformations of nitrogen-expanded austenite studied with in situ synchrotron X-ray diffraction, J. Appl. Crystallogr. 47 (2014) 819-826.

[31] B.K. Brink, Synthesis and characterization of homogeneous interstitial solutions of nitrogen and carbon in iron-based lattices, PhD Thesis. (2015) Technical University of Denmark.

[32] K. Fabian, V.P. Shcherbakov, S.A. McEnroe, Measuring the Curie temperature, Geochemistry, Geophys. Geosystems. 14 (2013) 947-961.

[33] D.C. Cook, Strain induced martensite formation in stainless steel, Metall. Trans. A. 18 (1987) 201-210.

[34] K. Oda, K. Umezus, H. Ino, Interaction and arrangement of nitrogen atoms in FCC $\gamma$ iron, J. Phys. Condens. Matter. 2 (1990) 10147-10158.

[35] J. Oddershede, T.L. Christiansen, K. Ståhl, M.A.J. Somers, Extended X-ray absorption fine structure investigation of nitrogen stabilized expanded austenite, Scr. Mater. 62 (2010) 290-293.

[36] E.L.P.Y. Blancá, J. Desimoni, N.E. Christensen, H. Emmerich, S. Cottenier, The 
magnetization of $\gamma^{\prime}$-Fe 4 N: theory vs. experiment, Phys. Status Solidi B. 246 (2009) 909-928.

[37] L.D. Flansburg, N. Hershkowitz, Magnetism in Austenitic Stainless Steels, J. Appl. Phys. 41 (1970) 4082-4086.

[38] M.A.J. Somers, N.M. van der Pers, D. Schalkoord, E.J. Mittemeijer, Dependence of the Lattice Parameter of $\gamma$ ' Iron Nitride, Fe4N1-X, on Nitrogen Content; Accuracy of the Nitrogen Absorption Data, Metall. Mater. Trans. A. 20 (1989) 1533-1539.

[39] I. Fall, J.M.R. Génin, Mossbauer analysis of Fe-N austenites, Hyperfine Interact. 69 (1991) 513-516.

[40] J.C. Jiang, E.I. Meletis, Microstructure of the nitride layer of AISI 316 stainless steel produced by intensified plasma assisted processing, J. Appl. Phys. 88 (2000) 40264031.

[41] M. Sifkovits, H. Smolinski, S. Hellwig, W. Weber, Interplay of Chemical Bonding and Magnetism in Fe4N, Fe3N and Fe2N, J. Magn. Magn. Mater. 204 (1999) 191-198.

[42] W. Pepperhoff, M. Acet, Const. Magn. Iron Its Alloy., Berlin Heidelberg: Springer, 2001: pp. 104-115.

[43] M. Hayase, M. Shiga, Y. Nakamura, Spontaneous Volume Magnetostriction and Lattice Constant of Face-Centered Cubic Fe-Ni and Ni-Cu Alloys, J. Phys. Soc. Japan. 34 (1973) 925-933.

[44] D. Wu, H. Kahn, J.C. Dalton, G.M. Michal, F. Ernst, a. H. Heuer, Orientation dependence of nitrogen supersaturation in austenitic stainless steel during lowtemperature gas-phase nitriding, Acta Mater. 79 (2014) 339-350.

[45] C. Tromas, J.C. Stinville, C. Templier, P. Villechaise, Hardness and elastic modulus gradients in plasma-nitrided 316L polycrystalline stainless steel investigated by nanoindentation tomography, Acta Mater. 60 (2012) 1965-1973. 


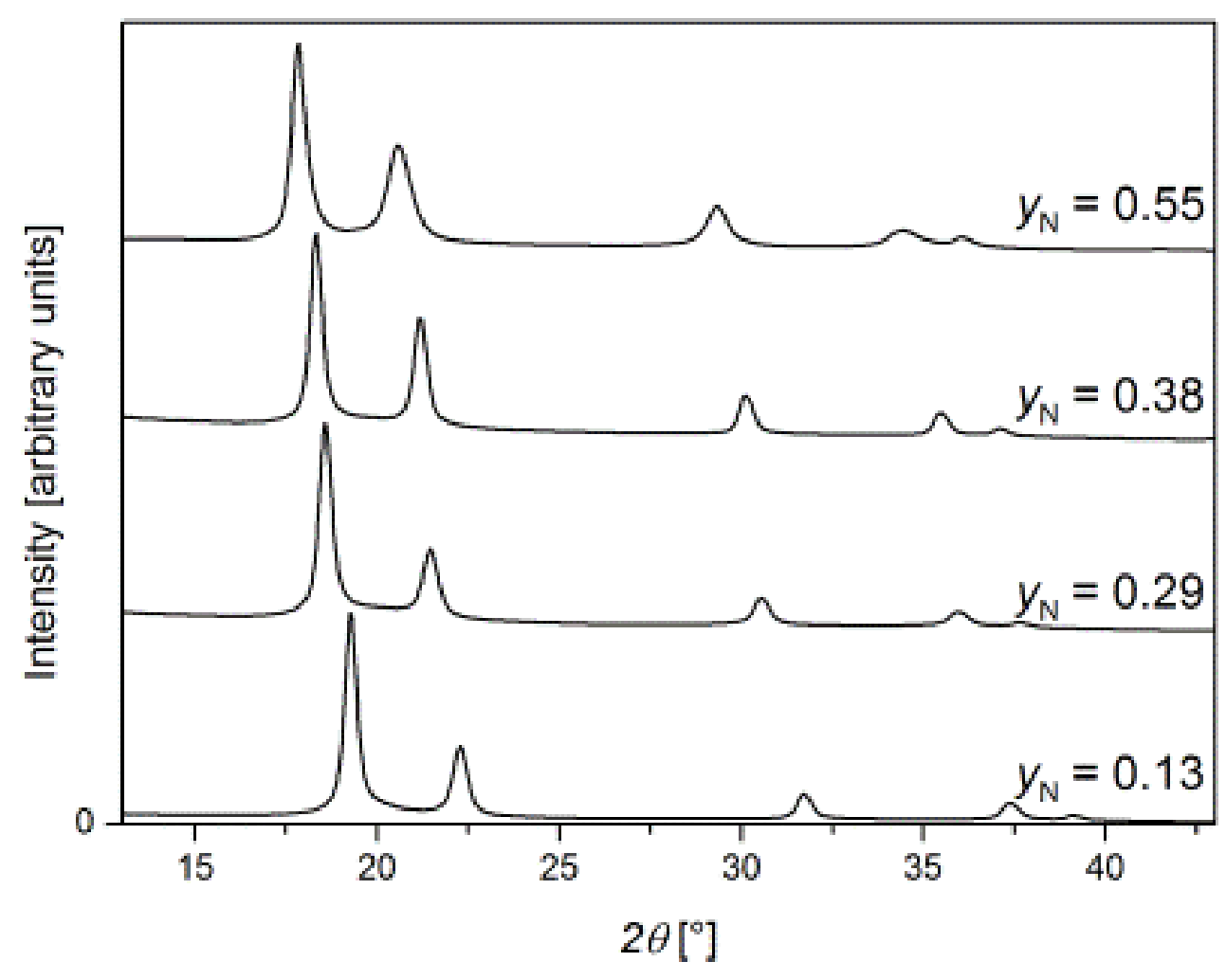

Fig. 1. X-ray diffractograms of $12.5 \mu \mathrm{m}$ AISI 316 foils annealed at $1323 \mathrm{~K}$ and nitrided in $\mathrm{NH}_{3} / \mathrm{H}_{2}$ gas mixtures at $693 \mathrm{~K}$. Nitriding potentials less than infinity were applied after full saturation was achieved. Increasing nitrogen content causes increasing shifts of reflections towards lower diffraction angle $(2 \theta)$. 

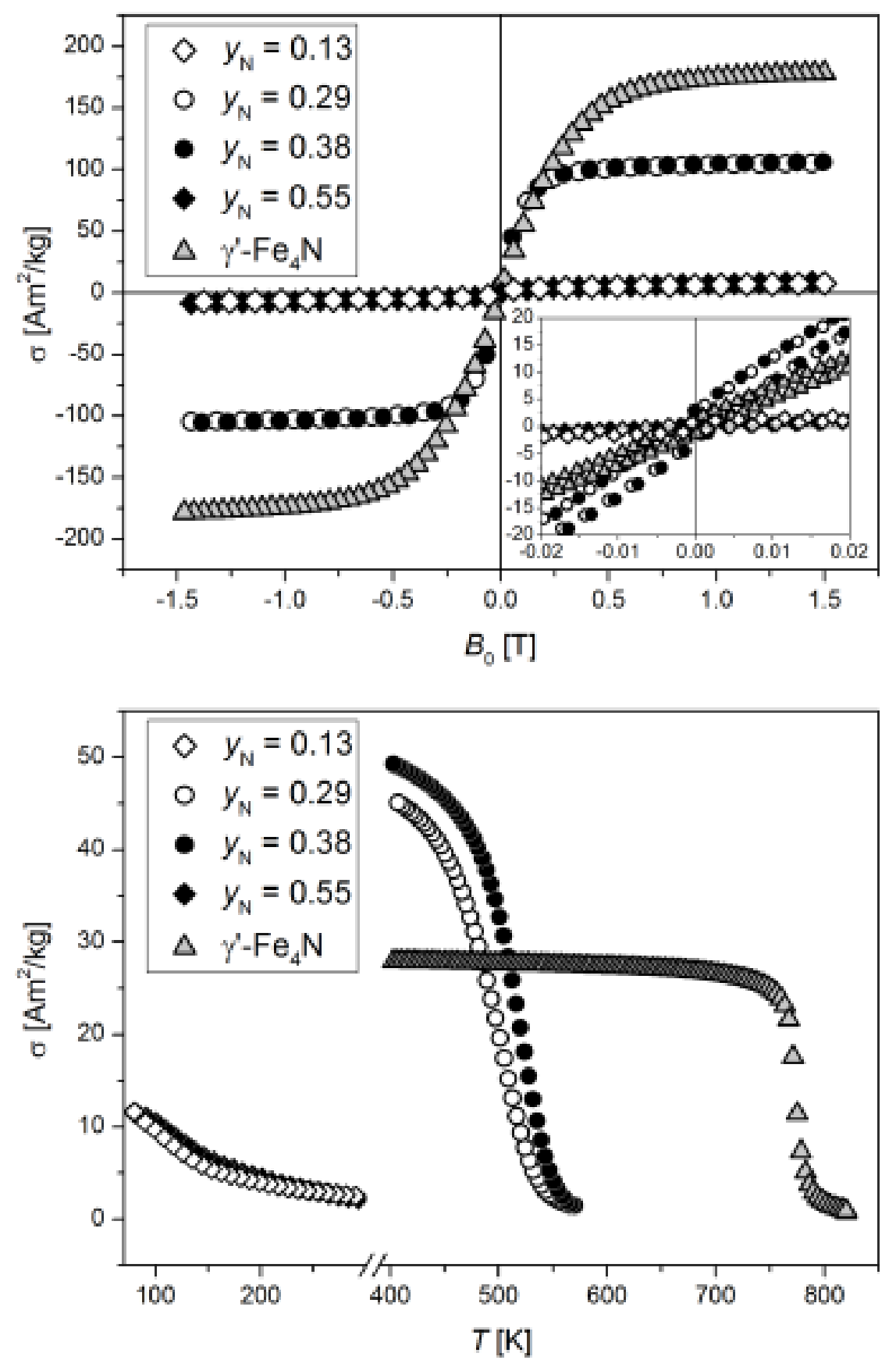

Fig. 2. a) Magnetic hysteresis curves for expanded austenite and $\gamma^{\prime}-\mathrm{Fe}_{4} \mathrm{~N}$ at room temperature and $b$ ) specific magnetization versus temperature at $B_{0}=0.05 \mathrm{~T}$ measured at a cooling rate of $1.5 \mathrm{~K} / \mathrm{min}$. For clarity only every $30^{\text {th }}$ measurement point or less is shown except for the inset in $a$ ). Note the break in the temperature scale in $b$ ). 

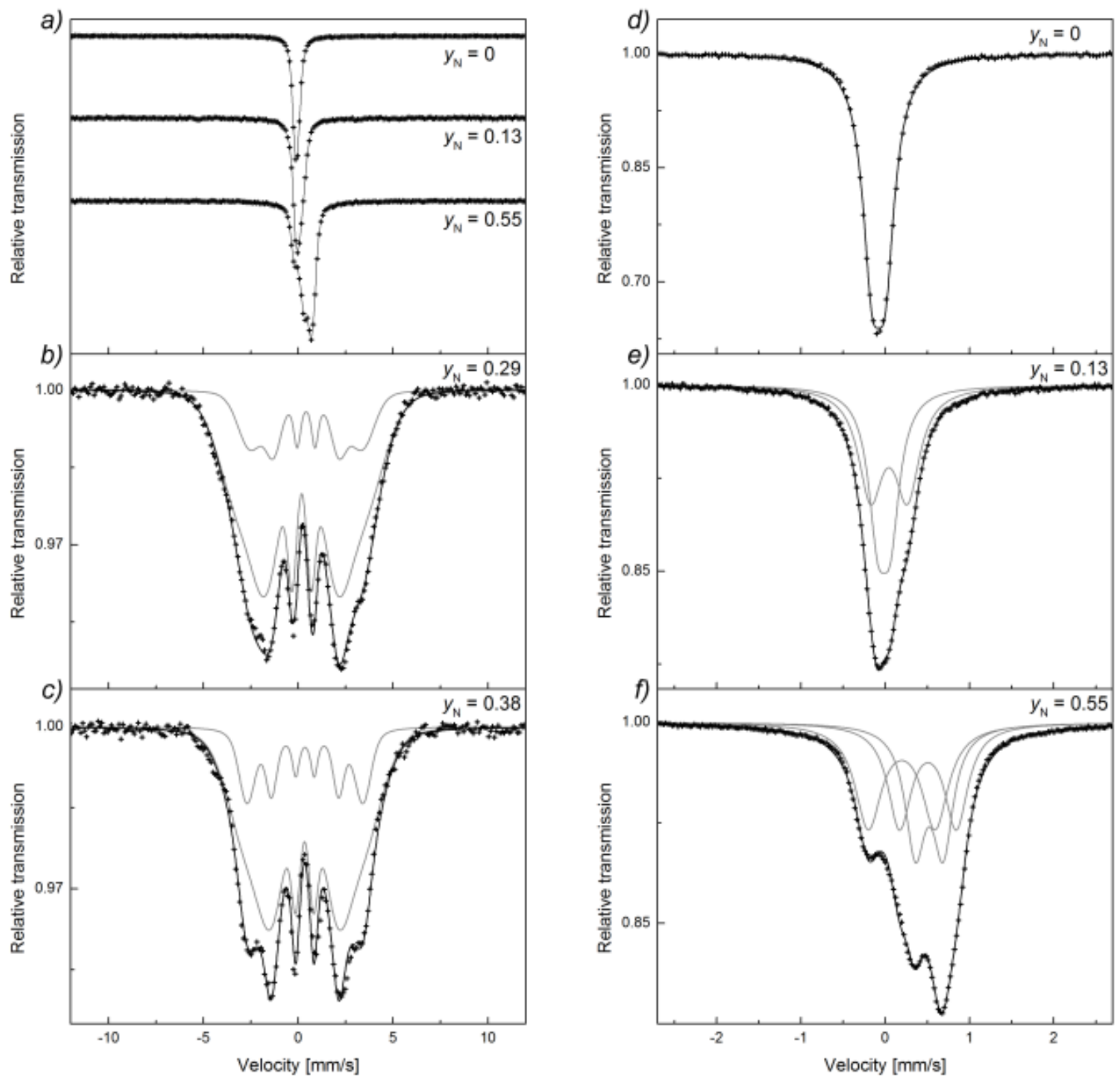

Fig. 3. Mössbauer spectra recorded at room temperature. a) Comparison of AISI 316 austenitic stainless steel $\left(y_{N}=0\right)$ and expanded austenite with low $\left(y_{N}=0.13\right)$ and high $\left(y_{N}=\right.$ $0.55)$ nitrogen content. $b+c)$ Spectra and fits for intermediate nitrogen contents $\left(y_{N}=0.29\right.$ and 0.38). $d$-f) Fits of spectra recorded at a reduced velocity range for AISI 316, low and high nitrogen contents. Fits are presented as black lines and the individual sextet and doublet components as grey lines. 

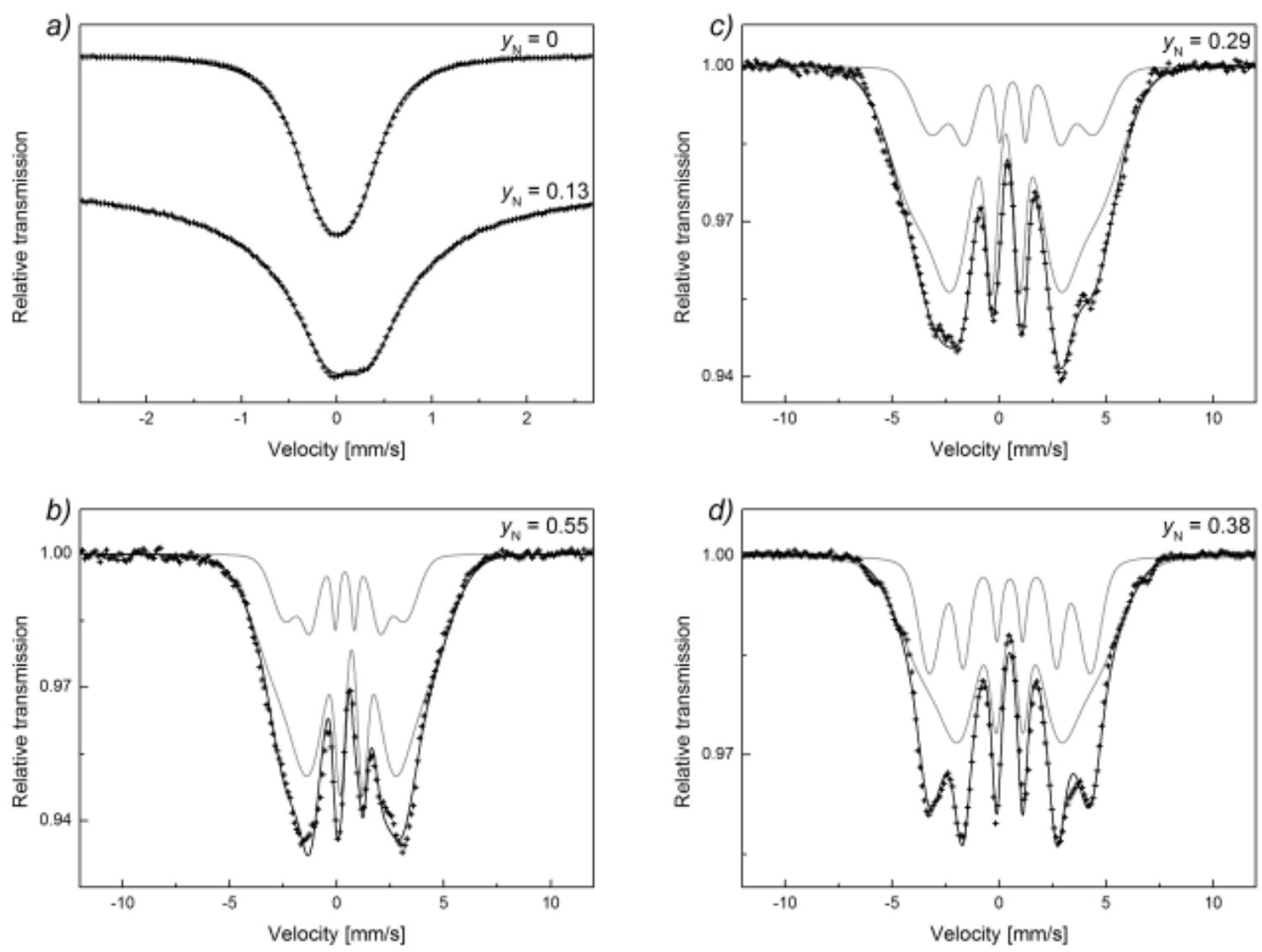

Fig. 4. Mössbauer spectra recorded at 15 K. a) Comparison of AISI 316 austenitic stainless steel $\left(y_{N}=0\right)$ and expanded austenite with low $\left(y_{N}=0.13\right)$ nitrogen content fitted with a single sextet. $b$ - $d$ ) Spectra and fits for intermediate and high nitrogen contents $\left(y_{\mathrm{N}}=0.29\right.$, 0.38 and 0.55 ). Fits are presented as black lines and the individual sextet components as grey lines. 


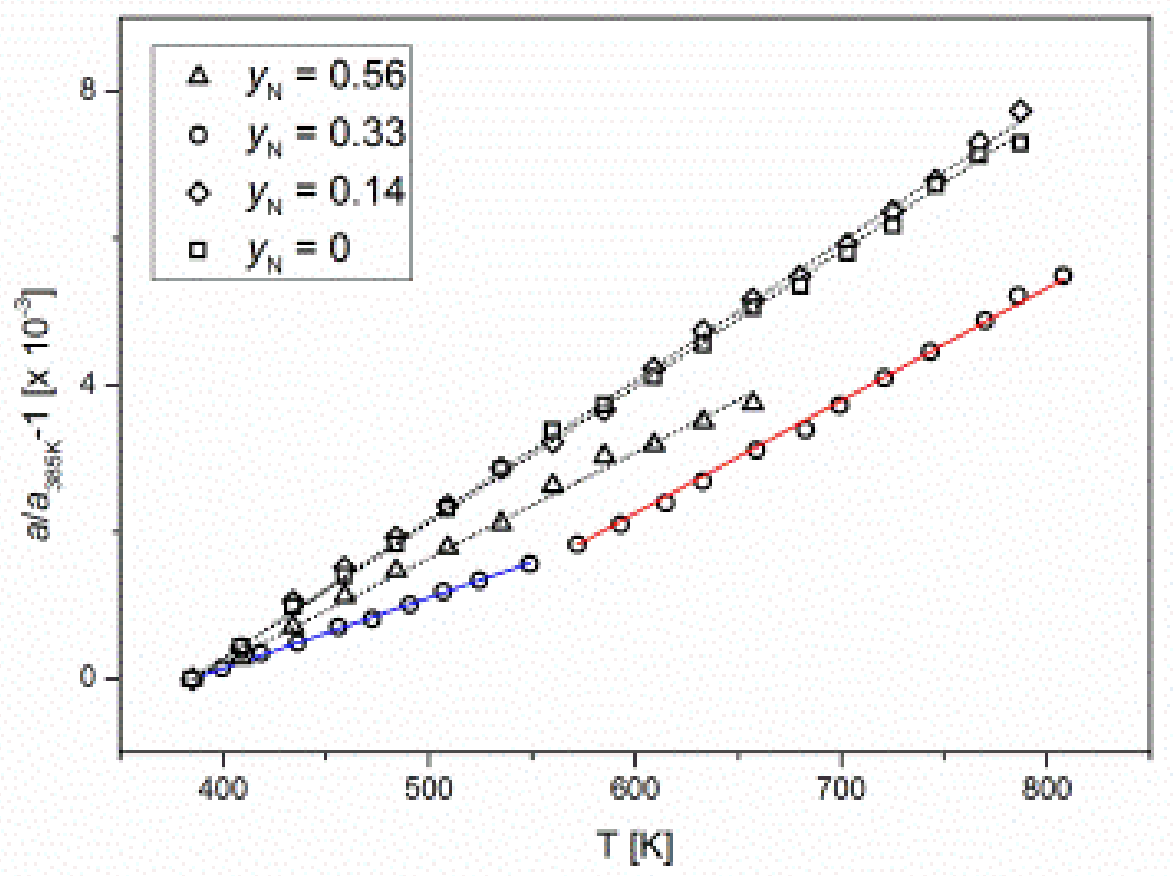

Fig. 5. Relative thermal expansion for expanded austenite. For comparison with previously obtained values [30], lattice parameters are scaled by the corresponding value at $385 \mathrm{~K}$. Fits are given as lines. For the current sample $\left(y_{\mathrm{N}}=0.33\right)$ two distinct linear regions are observed. 

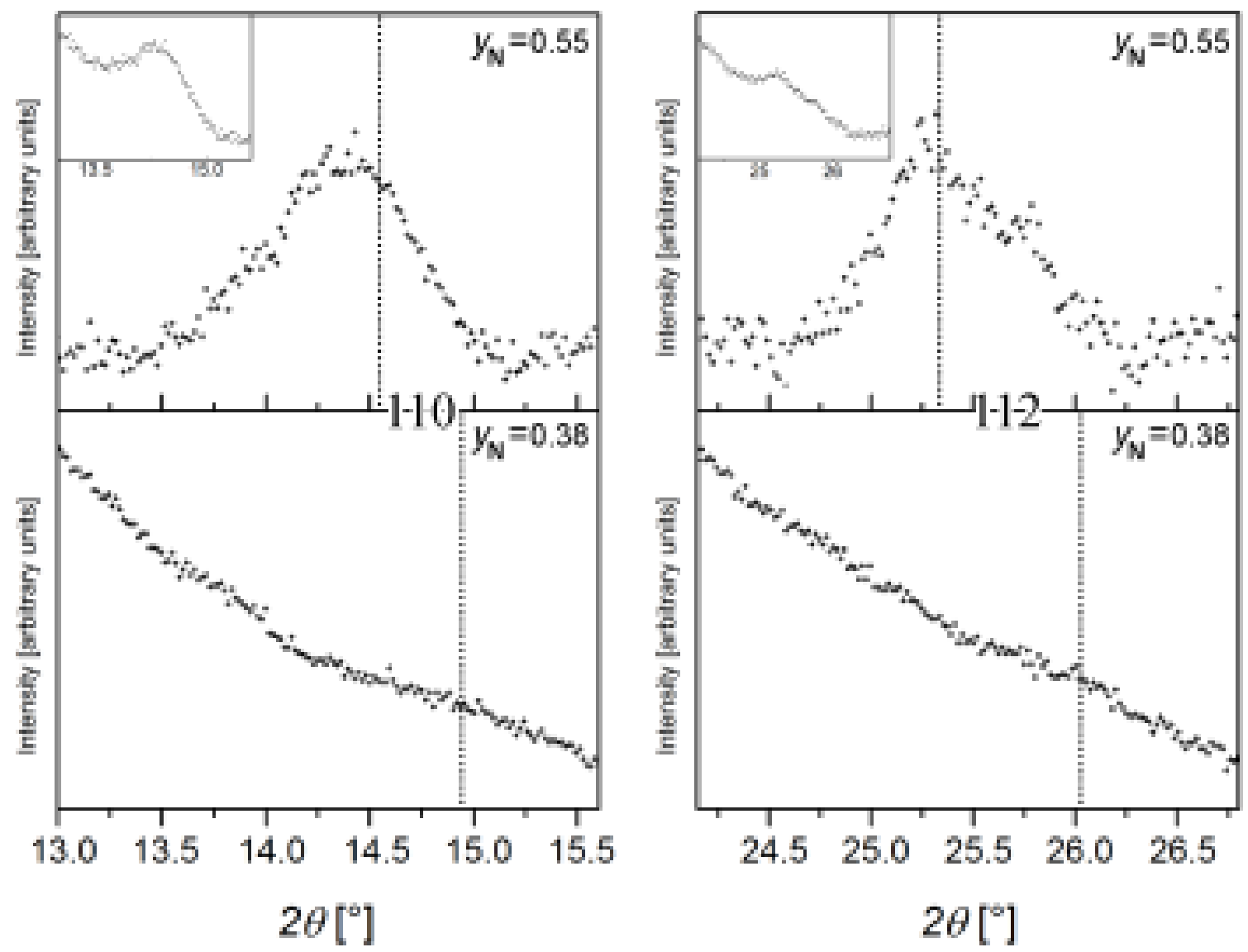

Fig. 6. X-ray diffractogram (Mo Ka radiation) of expanded austenite with $a$ ) $y_{\mathrm{N}}=0.55$ and $b$ ) ideal positions of 110 and 112 reflections, marked as vertical lines for $y_{N}=0.55$ and $y_{N}=$ 0.38. Diffraction peaks at these positions are only observed for $y_{N}=0.55$ (background is subtracted but shown in the insets). 


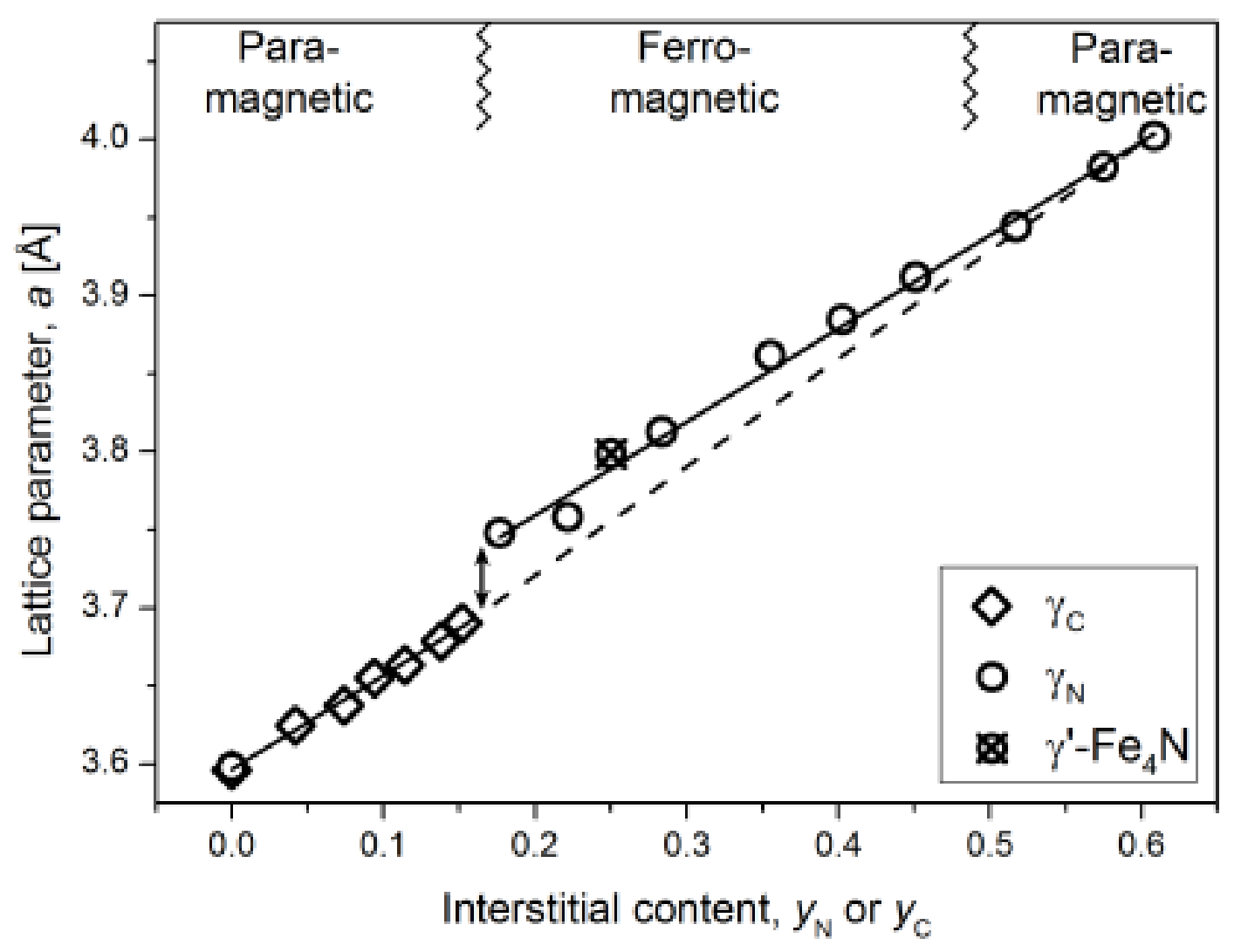

Fig. 7. Lattice parameters versus interstitial content for nitrogen $\left(\gamma_{N}\right)$ and carbon $\left(\gamma_{C}\right)$ expanded austenite and $\gamma^{\prime}-\mathrm{Fe}_{4} \mathrm{~N}$, with reported linear relations drawn as full lines $[1,23]$. Para- and ferromagnetic regions are indicated and the dashed line connects the two paramagnetic regions. Arrows mark the discrepancy in lattice parameters due to spontaneous volume magnetostriction, which is gradually decreased on approaching the paramagnetic region at high interstitial contents. 
